\title{
Frequent mutations and amplifications of the PIK3CA gene in pituitary tumors
}

\author{
Yong Lin, Xiaofei Jiang, Ye Shen ${ }^{1}$, Min Li, Huili Ma, Mingzhao Xing ${ }^{2}$ \\ and Yuan Lu
}

Department of Laboratory Medicine, Huashan Hospital, Shanghai Medical College, Fudan University, 12 Central Urumqi Road, Shanghai 200040, People's Republic of China

${ }^{1}$ Institute of Endocrinology and Diabetologia, Fudan University, Shanghai 200040, People's Republic of China

${ }^{2}$ Division of Endocrinology and Metabolism, The Johns Hopkins University School of Medicine, Baltimore, Maryland 21287, USA

(Correspondence should be addressed to Y Lu; Email: yuanlu@hsh.stn.sh.cn)

\begin{abstract}
Genetic alterations in the PIK3CA gene of the phosphoinositide 3-kinase (PI3K)/AKT pathway have been found in many human tumors, but they have not been explored in pituitary tumors. We undertook the present study to explore mutations and amplifications of the PIK3CA gene in pituitary tumors. DNA sequencing and real-time quantitative PCR were used to examine mutations and amplifications respectively, on genomic DNA samples isolated from 353 cases of pituitary tumors, and immunohistostaining was used to assess PIK3CA expression. About 8 out of $91(9 \%)$ invasive pituitary tumors versus 0 out of $262(0 \%)$ noninvasive tumors were found to harbor somatic mutations in exons 9 and 20 of the PIK3CA gene $(P<0.001)$, and the mutation was associated with increased disease recurrence. Genomic PIK3CA amplifications (defined as $\geq 4$ copies) were observed in both invasive and noninvasive tumors, with a prevalence of around $20-40 \%$ in various types of pituitary tumors. PIK3CA protein overexpression was observed in cases with high PIK3CA copy number. RAS mutations were also examined and found in 6 out of the $91(7 \%)$ invasive tumors. PIK3CA amplifications were mutually exclusive with PIK3CA or RAS mutations $(P<0.001)$. This study demonstrated for the first time relatively common PIK3CA mutations and amplifications as well as RAS mutations and their tendency of mutual exclusivity in pituitary tumors. The data provide strong genetic evidence supporting a role of the PI3K/AKT signaling pathway in the tumorigenesis of pituitary tumors, particularly the invasive types.
\end{abstract}

Endocrine-Related Cancer (2009) 16 301-310

\section{Introduction}

The phosphoinositide 3-kinase (PI3K)/AKT signaling pathway regulates fundamental cellular process linked to tumorigenesis, including cell proliferation, adhesion, survival, motility, and spreading (Samuels \& Ericson 2006). PI3Ks are lipid kinases that increase intracellular pools of phosphatidylinositol 3,4,5-triphophate (PIP3) by phosphorylating its precursor, phosphatidylinositol 4, 5-bisphosphate (PIP2), a process antagonized by the lipid phosphatase PTEN that converts PIP3 back to PIP2. PIP3 serves as an anchor for pleckstrin homology domain-containing proteins that in turn contribute to the recruitment and activation of a wide range of downstream targets, including AKT (Karakas et al. 2006). Class IA PI3Ks, existing as heterodimers of a p110 catalytic subunit and a p85 regulatory subunit, are widely expressed and most important in cellular function (Karakas et al. 2006, Samuels \& Ericson 2006).

The PIK3CA gene, which encodes the catalytic subunit PIK3CA of class IA PI3K is located on chromosome 3q26.3 and consists of 20 exons. Many mutations of the PIK3CA gene were found to increase enzymatic activity of PIK3CA, activate the AKT signaling, and allow growth factor-independent growth, invasion, and metastasis of cancer cells (Samuels et al. 2004, Kang et al. 2005, Samuels \& Ericson 2006). Two PIK3CA mutational 'hotspots' were found in exons 9 and 20 and activating mutations in these regions were seen in many human cancers (Samuels et al. 2004, Hayes et al. 2006, Karakas et al. 2006, Kozaki et al. 2006, Phillips et al. 2006, Qiu et al. 2006, Schönleben et al. 2006, Qiu et al. 2008, Santarpia et al. 2008). Genetic amplification of the PIK3CA gene was also 
seen in many tumors, including ovarian cancer (Shayesteh et al. 1999), cervical cancer (Ma et al. 2000), brain tumors (Hui et al. 2001), non-small cell lung cancer (Massion et al. 2002), squamous cell carcinoma (Woenckhaus et al. 2002), gastric carcinoma (Byun et al. 2003), esophageal adenocarcinoma (Miller et al. 2003), thyroid tumors (Wu et al. 2005), oral squamous cell carcinoma (Kozaki et al. 2006), head and neck squamous cell carcinoma (Qiu et al. 2006), and anal squamous cell carcinoma (Patel et al. 2007). Genetic amplifications of the PIK3CA gene were associated with increased PIK3CA expression, PI3K activity, and phosphorylation and activation of AKT (Shayesteh et al. 1999, Ma et al. 2000, Massion et al. 2002, Byun et al. 2003, Samuels et al. 2004, Wu et al. 2005, Kozaki et al. 2006).

Pituitary tumors are common endocrine neoplastic diseases. Multiple tumor-promoting factors or signaling pathways are known to be involved, through interplay, in pituitary tumorigenesis and pathogenesis (Ezzat \& Asa 2006). The PI3K/AKT signaling pathway also seems to be involved in this process as the expression of PI3K was shown to be increased in pituitary tumors (Grossman \& Korbonits 2004). However, genetic alterations, which are the driving force for human tumorigenesis and pathogenesis, have in general been unknown in pituitary tumors. Given the frequent mutations and amplifications of the PIK3CA gene in many human tumors and given the poor understanding of the genetic basis of pituitary tumors, in the present study we were interested in investigating these genetic alterations in a large series of pituitary tumors.

\section{Materials and methods}

\section{Human pituitary tissues and DNA isolation}

Surgical samples were obtained from 353 patients with pituitary tumors, who underwent resection of their tumors at Huashan Hospital, Fudan University, Shanghai. The study was approved by the Ethics Committee of Huashan Hospital and informed consents were obtained from all patients for the collection and use of tissues for this study. The tumors were classified according to the Hardy's radiological classification scheme (Wilson 1984). A total of 262 noninvasive pituitary tumors, 91 invasive pituitary tumors, 9 pituitary hyperplasia, 3 randomly chosen normal pituitary tissues from paraffin blocks, and 8 normal tissues matched to tumor tissues were obtained at the Institute of Endocrinology and Diabetology and the Department of Neuropathology, Institute of Neurology, Fudan University, Shanghai between
2001 and 2005. Genomic DNA was extracted from formalin-fixed, paraffin-embedded tumor specimens using the Qiagen DNeasy Tissue Kit (Qiagen).

\section{Laser-captured microdissection}

Normal tissues adjacent to the margins of the tumor confirmed by the pathologist were microdissected to match the tumors positive for mutations. Whenever necessary, the paraffin-embedded tissues were microdissected to increase the proportion of tumor or normal cells. Formalin-fixed and paraffin-embedded pituitary tissues were subjected to Laser-captured microdissection with the Leica Microsystems Wetzlar GmbH (Germany) according to the manufacturer's protocols. Briefly, $5 \mu \mathrm{m}$ thick serial sections were prepared from each sample. To avoid cross-contamination of samples, a new microtome blade (Leica) was used for each case. The area of the microtome around the blade was thoroughly cleaned with $70 \%(\mathrm{v} / \mathrm{v})$ ethanol between samples (Kasai et al. 2000). The sections were stained with hematoxylin and eosin (H\&E). Each section was overlaid with a thermoplastic membrane and cells were captured by focal melting of the membrane by laser activation. Each of the captured samples contained about 100-150 tumor cells. DNA from laser microdissected tissue fractions was extracted and isolated with QIAamp DNA Micro Kit (Qiagen) following the manufacturer's instructions.

\section{Mutation analysis of the PIK3CA gene}

As the vast majority of $P I K 3 C A$ gene mutations were found in exons 9 and 20, we focused our mutation analysis on these exons in pituitary tumors. For exon 9, the PCR amplification primers used were $5^{\prime}$-GATTGGTTCTTTCCTGTCTC- $3^{\prime}$ (sense) and $5^{\prime}$-AATAAAGAAAAAGAAGCAGAGAATC-3' (antisense). PCR was carried out in $50 \mu \mathrm{l}$ reaction mixture containing $40-80 \mathrm{ng}$ of genomic DNA, $25 \mu \mathrm{mol} / \mathrm{l}$ of each primer, $200 \mu \mathrm{mol} / 1$ deoxynucleotide triphosphates, $1 \times$ buffer, and 2.5 units of Hot Star TaqDNA polymerase (TaKaRa, Dalian, China). The mixture was heated for $3 \mathrm{~min}$ at $95^{\circ} \mathrm{C}$, followed by 35 cycles of denaturation (30 s at $\left.94{ }^{\circ} \mathrm{C}\right)$, annealing $\left(30 \mathrm{~s}\right.$ at $\left.52^{\circ} \mathrm{C}\right)$, and extension $(30 \mathrm{~s}$ at $72{ }^{\circ} \mathrm{C}$ ). The PCR products were electrophoresed on $1.2 \%$ agarose gels to ensure the integrity before purification and DNA sequencing on an ABI PRISM 3700 DNA Analyser (Applied Biosystems, Foster City, CA, USA) by United Gene Holding Ltd (Shanghai, China).

Exon 20 was analyzed by nested PCR-automated sequencing. The primers used to amplify the two amplicons were: $5^{\prime}$-AAAAGATGTTGGTAAGAGAAGTGAGAG-3' (sense) and 5'-AACCATCACTTTTTCCTTCTCCATCA-3' (antisense) for the first PCR; 
5'-AAGGTATTAACATCATTTGCTC-3' (sense) and $5^{\prime}$-CTTTTTGGACTTAAGGCATAAC-3' (antisense) for the second PCR. The cycle numbers for the first and second PCR were 15 and 35 respectively. Nested PCR and automated sequencing for exon 20 used the same reaction conditions as for exon 9. All mutated cases were confirmed by repeated PCR on a new DNA preparation and compared with the matching normal DNA.

\section{Mutation analysis for RAS genes}

All invasive tumor DNA were evaluated for point mutations at codons 12,13 , and 61 of $\mathrm{K}-, \mathrm{H}$-, and $N-R A S$ by direct DNA sequencing using the same PCR primer and reaction conditions described previously (Garcia-Rostan et al. 2003). The PCR products were electrophoresed on $1.2 \%$ agarose gels to ensure integrity before purification and DNA sequencing on an ABI PRISM 3700 DNA Analyser (Applied Biosystems) by United Gene Holding Ltd. Potential mutations were confirmed by a second round of PCR and sequencing.

\section{Copy number analysis of PIK3CA with real-time quantitative PCR}

PIK3CA gene amplification was assessed by real-time TaqMan quantitative PCR with primers to genomic sequences and compared with the signal obtained from the reference gene $\beta$-actin. Specific primers and probes for PIK3CA and $\beta$-actin genes were designed as previously described (Wu et al. 2005). PCR was carried out with TaqMan PCR Master Mix (Applied Biosystems Inc.) on an ABI Prism 7000 sequence detection system (Perkin-Elmer, Foster City, CA, USA) following the protocol described previously (Mambo et al. 2003). Samples were run in triplicates, and primers and probes to $\beta$-actin were run in parallel to standardize the input DNA. Three normal samples were also used on each assay, and their mean value was used to normalize the data and correct for inter-assay variation (Campbell et al. 2004). We analyzed copies of PIK3CA and $\beta$-actin on PIK3CA and $\beta$-actin standard curves derived from normal pituitary tissues respectively. The PIK3CA gene copy number was calculated by dividing its value by the $\beta$-actin value. Positive PIK3CA gene amplification was defined as a copy number of $\geq 4$. We confirmed the validity of our detection system by using serial dilutions of PMD18T-PIK3CA and PMD18-T- $\beta$-actin constructs with $10^{2}-10^{8}$ copies/ $\mu$ I DNA.

\section{Immunohistochemistry}

Immunohistochemical staining was performed on tissue sections to examine molecular markers of pituitary adenomas and protein expression of PIK3CA and Ki-67. Five micrometer sections of paraffin-embedded tissues containing at least $1 \mathrm{~cm}^{2}$ of tumor component from each sample were de-waxed and re-hydrated. Endogenous peroxidase activity was inactivated with $3 \% \mathrm{H}_{2} \mathrm{O}_{2}$. Antigenicity was retrieved by microwave heating of the samples in $10 \mathrm{mM}$ sodium citrate solution for $5 \mathrm{~min}$. After blocking nonspecific binding sites with $2.5 \%$ normal horse serum, the sections were incubated with the monoclonal antibody against PIK3CA (C73F8, Cell Signaling Technologies, Beverly, MA, USA). For other molecular markers of tumor types, monoclonal antibodies used included anti-ACTH (M3501, DakoCytomation Inc., Carpinteria, CA, USA), anti-LH (M3502, DakoCytomation Inc.), anti-TSH (M3503, DakoCytomation Inc.), and anti-FSH (M3504, DakoCytomation Inc.); and polyclonal antibodies included anti-hGH (A0570, DakoCytomation Inc.), anti-prolactin (A0569, DakoCytomation Inc.), and MIB-1 (M7240, Dako). Small nests containing up to 100 cells were identified randomly using high-power $(400 \times)$ microscopy and cells exhibiting distinctive cytoplasmic immunoreactivity were counted. Sections were counterstained with hematoxylin and evaluated by two pathologists in a blinded fashion, using standard criteria. The immunoreactivity for PIK3CA was evaluated on a semiquantitative scale considering both the percentage of positive cells (score: 0-4 for respectively, $<5,5-20,20-40,40-80,>80 \%)$ and the intensity (score: 0-3) of staining (Di Florio et al. 2007). The product of both yield a final immunostaining score $(-, 0 ;+, 1-4 ;++, 5-8$; and,$+++ 9-12)$, and - and + were recorded as negative and ++ and +++ recorded as positive. The immunostaining score for ACTH, LH, TSH, FSH, hGH, and PRL was determined according to the Dako system scale: negative $(-$ and +$)$ and positive $(++$ and +++$)$. The protein expression of Ki-67 was examined by immunohistochemical staining in 91 invasive pituitary tumors. The Ki-67 labeling index (LI) was calculated as the ratio of the labeled over total nuclear areas (Dubois et al. 2007).

\section{Statistical analysis}

The Pearson $\chi^{2}$ test was used for association studies between PIK3CA mutations, PIK3CA amplification, and tumor invasiveness or recurrence. Associations among PIK3CA mutations, PIK3CA amplification, and $R A S$ mutations in invasive pituitary tumors were 
assessed by McNemar's $\chi^{2}$ test. Data on the distribution of PIK3CA mutations among histologic subtypes of pituitary tumors were tested for significance using the Fisher's exact test. A $P$ value $<0.05$ was considered to be significant. All statistical analyses were performed by the Stata v10.0 software (Computer Resource Center Inc., Chicago, IL, USA).

\section{Results}

Among the 353 pituitary tumors analyzed, PIK3CA mutations in exons 9 and 20 were found in $8 / 353$ $(2.3 \%)$ of the cases. These missense mutations cause amino acid changes in the protein with expected functional consequences. These PIK3CA mutations were found in $8 / 91(8.8 \%)$ invasive pituitary tumors and $0 / 262(0 \%)$ noninvasive pituitary tumors (Table 1 ). All invasive pituitary tumors with PIK3CA mutations were macroadenomas. The specific nucleotide change and corresponding amino acid substitution are shown in Fig. 1. The normal tissues matched for the eight tumors positive for PIK3CA mutations did not harbor any mutation, confirming the somatic nature of these mutations. Stratifying the invasive pituitary tumors according to immunophenotypes revealed similar distribution of the mutations in various types of tumors $(P=0.734)$, as summarized in Table 1 . Additional three randomly chosen normal pituitary tissues and nine pituitary hyperplasia samples showed no mutations in the PIK3CA gene (Table 1).
To search for alternative genetic mechanism of the PIK3CA gene that may potentially cause overactivation of the PI3K/AKT signaling pathway in pituitary tumors, we next assessed the PIK3CA copy number by real-time quantitative PCR in pituitary tumors. When a copy number of PIK3CA $\geq 4$ was defined as a positive amplification, we found PIK3CA amplifications in 69 out of $262(26.3 \%)$ noninvasive tumors, 30 out of 91 (32.9\%) invasive tumors, 0 out of $9(0 \%)$ pituitary hyperplasia samples, and 0 out of 11 normal pituitary tissues. There was no significant difference in the distribution of PIK3CA amplifications between the invasive and noninvasive pituitary tumors $(P=0.225$; Table 1). Similar PIK3CA amplifications were also found in different immunophenotypes of invasive $(P=0.977)$ and noninvasive $(P=0.953)$ pituitary tumors (Table 1 ).

Immunohistochemical staining was used to test whether PIK3CA gene amplification could cause increased protein expression of this gene. We performed immunohistochemical staining of PIK3CA in i) 20 pituitary tumors with $<4$ copies of the gene per cell, ii) 99 pituitary tumors with $\geq 4$ copies per cell, and iii) 3 normal pituitary tissues and 9 pituitary hyperplasia tissues with $<4$ copies per cell. As summarized in Table 2, none of the 20 tumors with $<4$ copies of PIK3CA gene was positive for PIK3CA immunoreactivity, while $26 / 99$ of the tumors with $\geq 4$ copies of the PIK3CA gene were positive for PIK3CA immunoreactivity and these were mostly those with a copy number of $\geq 7$. The normal pituitary tissues and

Table 1 Prevalence of PIK3CA mutation and amplification in various phenotypes of pituitary tumors, $n / N(\%)$

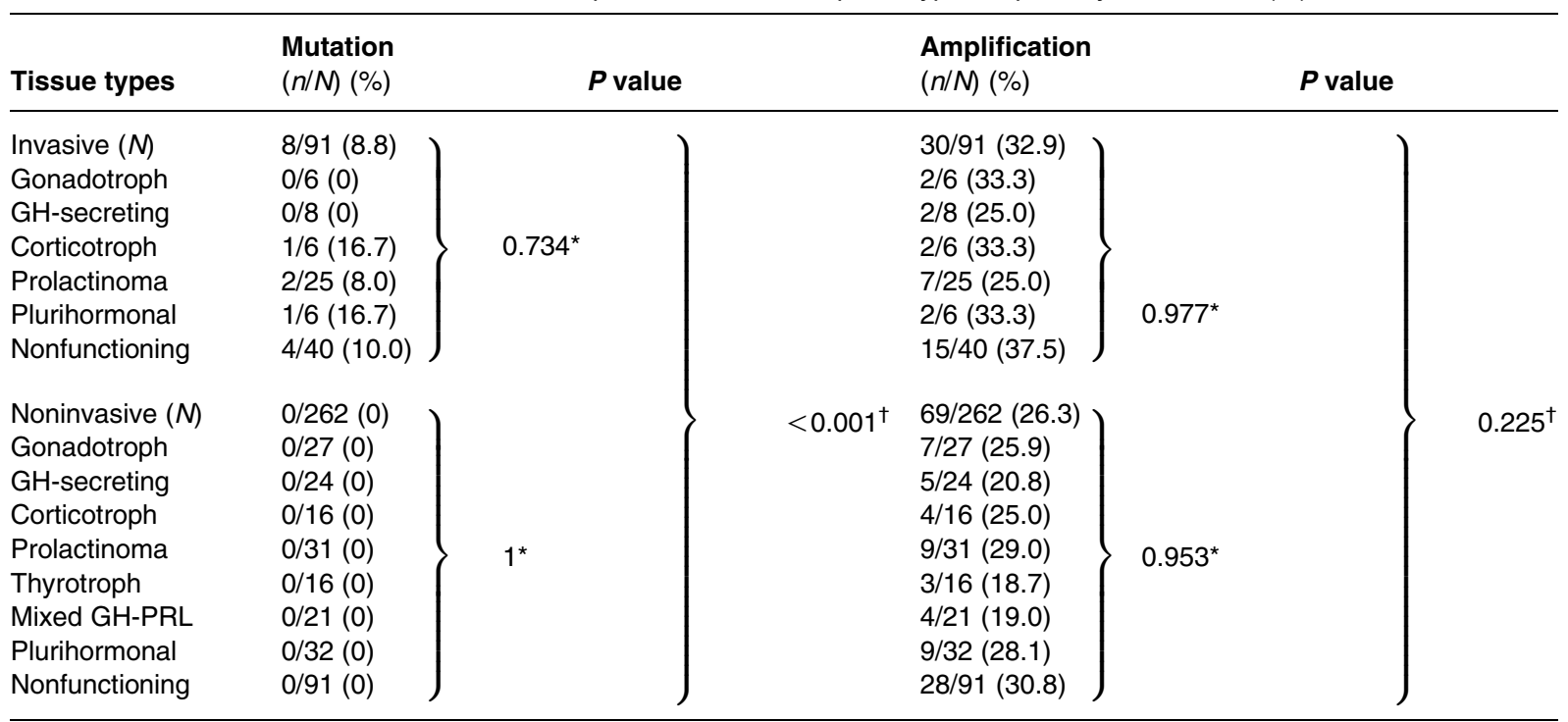

$\mathrm{GH}$, growth hormone; PRL, prolactin. * $P$ value was derived from comparisons among histologic subtypes of pituitary tumors.

${ }^{\dagger} P$ value was derived from comparisons between the invasive and noninvasive pituitary tumors. 

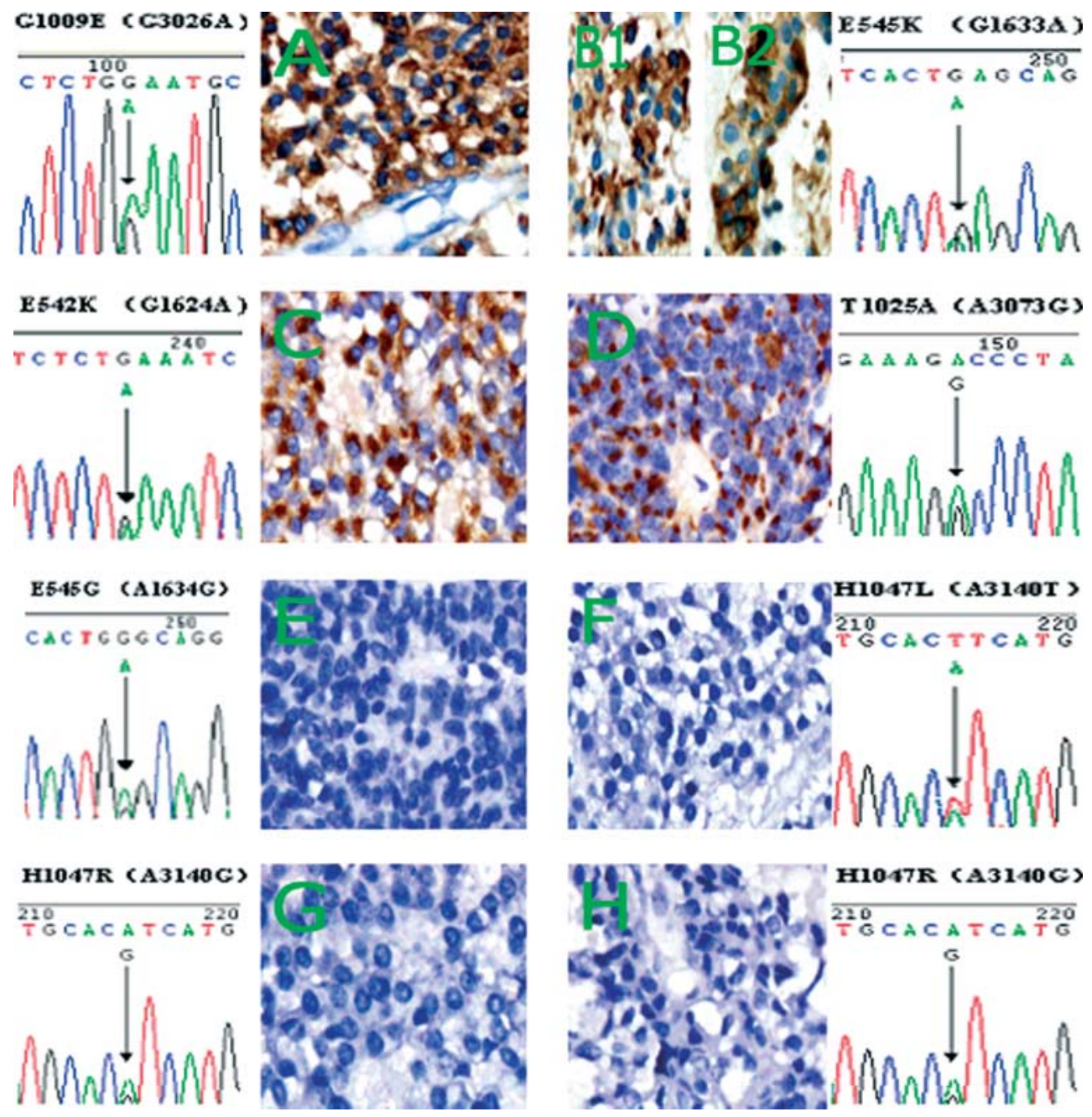

Figure 1 PIK3CA gene mutations in exons 9 and 20 and the corresponding histologic characteristics of the pituitary tumors. In each case, the DNA sequence of chromatogram showing the mutation status is next to the immunohistochemical staining of the corresponding tumor. Arrows indicate the location of missense mutations. The altered nucleotide and the amino acid substitution are indicated above each sequencing trace. (A) Corticotroph cell adenomas (immunohistostaining level,$+++ \times 40$ ); (B) plurihormonal adenomas (immunohistostaining level,$+++ \times 40$ ); (C) and (D) prolactinomas (immunohistostaining level,$+++ \times 40)$; $(E)-(G)$, and $(\mathrm{H})$ nonfunctioning adenomas (immunohistostaining level,$- \times 40$ ).

pituitary hyperplasia tissues were all negative or only weakly positive for PIK3CA immunoreactivity (Fig. 2). Overall, PIK3CA gene was significantly more strongly expressed in tumors carrying gene amplification than in those without gene amplification $(P<0.05)$. Expression of PIK3CA in invasive pituitary tumors with gene amplification was similar to that in noninvasive pituitary tumors $(P=0.923)$ (Table 2$)$.

Coexistence of the PIK3CA mutation and amplification was rare; the mutation was seen only in $1 / 30$ $(3.3 \%)$ invasive pituitary tumors and 0/69 (0\%) noninvasive pituitary tumors that harbored PIK3CA amplifications, suggesting a tendency of mutual exclusivity of the two genetic alterations in pituitary tumors $(P<0.001)$. PIK3CA mutations or amplifications were found in 37 out of the 91 $(40.7 \%)$ invasive pituitary tumors and 69 out of the $262(26.3 \%)$ noninvasive pituitary tumors.

We also examined mutations in the three $R A S$ oncogenes $(H-, K$-, and $N-R A S)$ in the 91 invasive pituitary tumors and found $R A S$ mutations in 6 out of the $91(6.6 \%)$ cases (Table 3). Among the 6 cases with RAS mutations, only 1 also harbored the PIK3CA mutation, and among the 85 cases with wild-type $R A S$, 7 harbored PIK3CA mutations. There seemed to be a mutual exclusivity between the PIK3CA and RAS mutations, but, probably due to the relatively small number of mutation-positive cases, their relationship could not be reliably concluded. PIK3CA amplifications were found in 0 out of the $5(0 \%)$ cases with $R A S$ 
Table 2 Relationship between PIK3CA expression and PIK3CA amplification, and invasiveness in pituitary tumor, $n / N(\%)$

\begin{tabular}{|c|c|c|c|}
\hline & \multicolumn{2}{|c|}{ PIK3CA expression $(n)^{\mathrm{a}}$} & \multirow[b]{2}{*}{$P$ value } \\
\hline & Positive & Negative & \\
\hline \multicolumn{4}{|c|}{ PIK3CA amplification $(N)^{\mathrm{b}}$} \\
\hline Positive & $26 / 99(26.3)$ & 73/99 (73.7) & $<0.05$ \\
\hline Negative & $0 / 20(0)$ & $20 / 20$ (100) & \\
\hline \multicolumn{4}{|c|}{ Tumor invasiveness $(N)$} \\
\hline Invasive & $7 / 30(23.3)$ & $23 / 30(76.7)$ & 0.923 \\
\hline Noninvasive & $19 / 69(27.5)$ & $50 / 69$ (72.5) & \\
\hline
\end{tabular}

aPositive PIK3CA expression is defined here as moderate to strong immunohistochemical staining, i.e., ++ and +++ staining, while negative expression is defined as negative or weak staining, i.e., - and + staining, as described in the Method.

${ }^{\mathrm{b}}$ Positive PIK3CA amplification is defined here as copy number of $\geq 4$, and negative is defined as copy number of $<4$.

mutations and 30 out of the $86(35 \%)$ cases with wildtype $R A S$, showing a tendency of mutual exclusivity of the two genetic alterations $(P<0.001)$.

In this study, 91 patients with invasive pituitary tumor undergoing microsurgery at the Department of Neurosurgery, Huashan Hospital, Shanghai Medical College, Fudan University were available for postoperative radiological follow-up. Disease recurrence after surgical resection was found in 5 out of the 8 (63\%) patients harboring the PIK3CA mutation versus 21 out of the $83(25 \%)$ patients with wild-type PIK3CA gene $(P=0.026)$. Immunohistochemical analysis for Ki-67 revealed that the invasive pituitary tumors with PIK3CA mutations $(n=8)$ had a mean Ki-67 LI of $2.796 \pm 1.953 \%$ and the invasive pituitary tumors without PIK3CA mutations $(n=83)$ had a mean Ki-67 LI of $2.451 \pm 1.426 \%$, showing an insignificant tendency of higher value in the former $(P=0.529)$.

\section{Discussion}

Although genetic alterations are commonly seen in the PI3K/AKT signaling pathway and play an important role in the tumorigenesis and pathogenesis of a large spectrum of human tumors, they have not been well investigated in pituitary tumors. In the present study, we explored these genetic alterations in a large cohort of pituitary tumors by examining the mutations and amplifications in two exons of the PIK3CA gene, which are the most common genetic alterations in the PI3K/AKT pathway in many other human tumors (Samuels \& Ericson 2006). We found relatively frequent mutations of the PIK3CA gene particularly in invasive pituitary tumors in exons 9 and 20, with a distribution pattern similar to those reported in other types of tumor (Broderick et al. 2004, Velho et al. 2005). Some of these mutations cause amino acid substitutions of E542K, E545K, and H1047R in the kinase domain of PIK3CA, which represent the three hotspots in this gene in most human cancers (Karakas

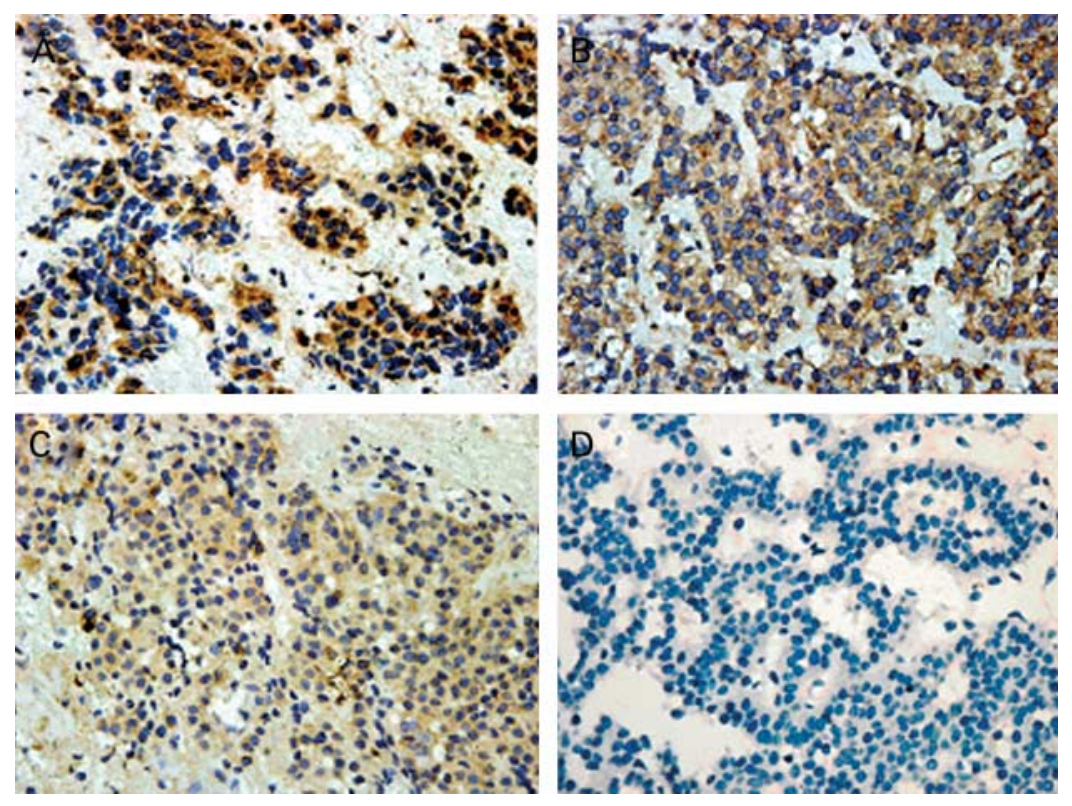

Figure 2 Immunohistochemical staining f PIK3CA: (A) A pituitary tumor with 28.83 PIK3CA copies per cell (immunohistostaining level +++ ); (B) a pituitary tumor with 9.92 PIK3CA copies per cell (immunohistostaining level ++ ); (C) a pituitary hyperplasia tissue with 1.97 PIK3CA copies per cell (immunohistostaining level +); and (D) a normal pituitary tissue with 1.58 PIK3CA copies per cell (immunohistostaining level - ). Magnification, $\times 40$. 
Table 3 RAS mutations in invasive pituitary tumors

\begin{tabular}{|c|c|c|c|c|c|}
\hline \multicolumn{3}{|c|}{ RAS mutations } & \multicolumn{3}{|c|}{ Invasive pituitary tumor types } \\
\hline $\begin{array}{l}\text { Exon/codon } \\
\text { (type of } R A S)\end{array}$ & $\begin{array}{l}\text { Nucleotide } \\
\text { substitution }\end{array}$ & Amino acid & Prolactinoma & GH-secreting & Corticotroph \\
\hline $1 / 12(H)$ & $\mathrm{GGC} \rightarrow \mathrm{GTC}$ & Gly $\rightarrow$ Val & 2 & 2 & \\
\hline $1 / 12(H)$ & $\mathrm{GGC} \rightarrow \mathrm{CGC}$ & Gly $\rightarrow$ Arg & 1 & & $1^{a}$ \\
\hline
\end{tabular}

aThis case also harbored PIK3CA mutation.

et al. 2006). These are activating mutations as evidenced by the higher lipid kinase activities associated with the PIK3CA mutant than the wild-type PIK3CA and the increased downstream AKT signaling activities (Samuels et al. 2004, Kang et al. 2005, Samuels \& Ericson 2006). Other mutations cause amino acid substitutions of E545G, G1009E, T1025A, and H1047L and their effects on the enzymatic activity or the transforming potential conferred by these mutations needs to be elucidated. It is interesting that the $P I K 3 C A$ mutations occurred exclusively in the invasive pituitary tumors but not in noninvasive pituitary tumors, suggesting that the PI3K/AKT pathway, when aberrantly activated by $P I K 3 C A$ mutations, may play a role in the invasiveness of pituitary tumors. There has been abundance of evidence supporting an important role of aberrantly activated PI3K/AKT pathway in tumor cell invasion and progression. For example, PTEN inhibited cell spreading and focal adhesion formation (Tamura et al. 1999, Musat et al. 2005, Tena-Suck et al. 2008), whereas cell clones containing PIK3CA mutant but not wild-type $P I K 3 C A$ showed an increased cell invasion ability (Samuels et al. 2005, Hayes et al. 2006, Samuels $\&$ Ericson 2006). Activation of the downstream AKT in the PI3K/AKT pathway was also shown to promote cell invasion (Vasko et al. 2004, Musat et al. 2005). Previous studies interestingly showed that PIK3CA mutations occurred at the point where benign colorectal tumor cells acquired the ability to invade (Samuels et al. 2004) or contributed to the invasion step from intramucosal carcinoma to invasive carcinoma in colorectal carcinogenesis (Miyaki et al. 2007). Given these data, our results on PIK3CA mutations in invasive pituitary tumors strongly suggest that these mutations may play an important role in the tumorigenesis and progression of a subgroup of pituitary tumors.

Our study demonstrated frequent genetic amplifications of the PIK3CA gene in pituitary tumors. The rare coexistence of $P I K 3 C A$ amplification and $P I K 3 C A$ mutation observed in the present study suggests that either genetic alteration may be an independently capable oncogenic event in pituitary tumors. PIK3CA amplifications were similarly seen in invasive and noninvasive pituitary tumors and various immunophenotypes, suggesting that this genetic alteration may be an early event and play a common role in promoting the tumorigenesis and progression of pituitary tumors as seen in other tumors (Woenckhaus et al. 2002, Miller et al. 2003, Wu et al. 2005, Kozaki et al. 2006). PIK3CA amplification was also shown to be associated with aggressiveness of tumors (Rooney et al. 1999, Estilo et al. 2003, Qiu et al. 2006), suggesting that this genetic alteration may play a different role in different tumors. PIK3CA amplifications were seen to be associated with increased expression of PIK3CA in other cancers (Shayesteh et al. 1999, Ma et al. 2000, Massion et al. 2002, Byun et al. 2003). Increased PIK3CA expression was previously also observed in pituitary tumors (Grossman \& Korbonits 2004), which can be explained by the PIK3CA amplification observed in the present study. Our present data showed a significant association of PIK3CA expression with the PIK3CA copy gain, particularly in those with a high copy number, a pattern consistent with the findings in lung cancer (Angulo et al. 2008).

The PIK3CA possesses an RAS binding domain and $\mathrm{PI} 3 \mathrm{~K}$ is a well-characterized immediate downstream effector of RAS (Garcia-Rostan et al. 2003, Karakas et al. 2006). Oncogenic RAS mutation therefore represents another genetic mechanism for aberrant activation of the PI3K/AKT signaling pathway in pituitary tumors (Suhardja et al. 2001). The occurrence of $R A S$ mutations found in invasive pituitary tumors in the present study is consistent with the previous report of a case of invasive pituitary tumor harboring the $R A S$ mutation (Pei et al. 1994). The rare coexistence of $R A S$ mutations with PIK3CA amplifications found in the present study is consistent with an independent role of each of these genetic alterations in pituitary tumorigenesis through aberrant activation of the PI3K/AKT pathway. Mutations in $P I K 3 C A$ and $R A S$ genes have been found to be mutually exclusive in some cancers. However, PIK3CA and RAS mutations coexisted in familial colorectal carcinoma (Velho et al. 2005), endometrial carcinoma (Fenic et al. 2007), head and neck squamous cell carcinoma (Murugan et al. 2008), 
and anaplastic thyroid cancer (Santarpia et al. 2008). In this study, we show a strong tendency but insignificant coexistence of PIK3CA and RAS mutations in invasive pituitary tumors.

We found a larger tumor size and a higher recurrence prevalence in invasive pituitary tumors with mutant $P I K 3 C A$ gene than in invasive pituitary tumors with wild-type $P I K 3 C A$ gene, consistent with previous reports on the predicting value of $P I K 3 C A$ mutation for poorer outcomes of other tumors (Kato et al. 2007, Lai et al. 2008). The proliferating cell nuclear antigen $\mathrm{Ki}-67 \mathrm{LI}$ represents a major prognostic indicator for pituitary adenomas (Kontogeorgos 2005, 2006). Our study showed that invasive pituitary tumors with PIK3CA mutations were associated with a tendency of higher expression level of $\mathrm{Ki}-67 \mathrm{LI}$, indicating increased cell proliferation. Thus, our current results revealed a prognostic value of PIK3CA mutation in pituitary tumors and suggest that patients with PIK3CA mutations in pituitary tumors should be followed more vigilantly.

In summary, we explored genetic alterations in the PIK3CA gene in a large series of pituitary tumors and found relatively common mutations and amplifications of this gene, with the former being preferentially found in invasive tumors and associated with increased cell proliferation and recurrence. The PIK3CA copy gain was associated with increased PIK3CA protein expression. The tendency of mutual exclusivity between PIK3CA amplifications and PIK3CA or RAS mutations suggests their independent oncogenic potentials in pituitary tumors. Thus, the present study provides strong genetic evidence that the PI3K/AKT signaling pathway may play an important role in the tumorigenesis of a subgroup of pituitary tumors.

\section{Declaration of interest}

The authors declare that there is no conflict of interest that would prejudice the impartiality of this scientific work.

\section{Funding}

This work was funded by a clinical research grant from Shanghai Municipal Health Bureau.

\section{Acknowledgements}

We are grateful to Prof. Yin Wang and Prof. Renlian Hu for their support and assistance in tumor sample preparation and data analysis; we also thank Dr Jin Xu and Dr Ming Xu for their critical reading of the manuscript and Dr Lewis Cantley (Harvard Medical School) for his thoughtful discussion and comments.

\section{References}

Angulo B, Suarez-Gauthier A, Lopez-Rios F, Medina PP, Conde E, Tang M, Soler G, Lopez-Encuentra A, Cigudosa JC \& Sanchez-Cespedes M 2008 Expression signatures in lung cancer reveal a profile for EGFR-mutant tumours and identify selective PIK3CA overexpression by gene amplification. Journal of Pathology 214 347-356.

Broderick DK, Di C, Parrett TJ, Samuels YR, Cummins JM, McLendon RE, Fults DW, Velculescu VE, Bigner DD \& Yan H 2004 Mutations of PIK3CA in anaplastic oligodendrogliomas, high-grade astrocytomas, and medulloblastomas. Cancer Research 64 5048-5050.

Byun DS, Cho K, Ryu BK, Lee MG, Park JI, Chae KS, Kim HJ \& Chi SG 2003 Frequent monoallelic deletion of PTEN and its reciprocal associatioin with PIK3CA amplification in gastric carcinoma. International Journal of Cancer 104 318-327.

Campbell IG, Russell SE, Choong DY, Montgomery KG, Ciavarella ML, Hooi CS, Cristiano BE, Pearson RB \& Phillips WA 2004 Mutation of the PIK3CA gene in ovarian and breast cancer. Cancer Research 64 7678-7681.

Dubois S, Guyétant S, Menei P, Rodien P, Illouz F, Vielle B \& Rohmer V 2007 Relevance of Ki-67 and prognostic factors for recurrence/progression of gonadotropic adenomas after first surgery. European Journal of Endocrinology 157 $141-147$.

Estilo CL, O-Charoenrat P, Ngai I, Patel SG, Reddy PG, Dao S, Shaha AR, Kraus DH, Boyle JO, Wong RJ et al. 2003 The role of novel oncogenes squamous cell carcinoma-related oncogene and phosphatidylinositol 3-kinase $\mathrm{p} 110 \alpha$ in squamous cell carcinoma of the oral tongue. Clinical Cancer Research 9 2300-2306.

Ezzat S \& Asa SL 2006 Mechanisms of disease: the pathogenesis of pituitary tumors. Nature Clinical Practice. Endocrinology \& Metabolism 2 220-230.

Fenic I, Steger K, Gruber C, Arens C \& Woenckhaus J 2007 Analysis of PIK3CA and AKT/protein kinase B in head and neck squamous cell carcinoma. Oncology Reports 18 253-259.

Di Florio A, Capurso G, Milione M, Panzuto F, Geremia R, Delle Fave G \& Sette C 2007 Src family kinase activity regulates adhesion, spreading and migration of pancreatic endocrine tumour cells. Endocrine-Related Cancer 14 111-124.

Garcia-Rostan G, Zhao H, Camp RL, Pollan M, Herrero A, Pardo J, Wu R, Carcangiu ML, Costa J \& Tallini G 2003 Ras mutations are associated with aggressive tumor phenotypes and poor prognosis in thyroid cancer. Journal of Clinical Oncology 21 3226-3235.

Grossman AB \& Korbonits M 2004 AKTing and cycling: a tale of the pituitary. Hormone Research 62 117-123.

Hayes MP, Wang H, Espinal-Witter R, Douglas W, Solomon GJ, Baker SJ \& Ellenson LH 2006 PIK3CA and PTEN mutations in uterine endometrioid carcinoma and complex atypical hyperplasia. Clinical Cancer Research 12 5932-5935. 
Hui AB, Lo KW, Yin XL, Poon WS \& Ng HK 2001 Detection of multiple gene amplifications in glioblastoma multiforme using array-based comparative genomic hybridization. Laboratory Investigation 81 717-723.

Kang S, Bader AG \& Vogt PK 2005 Phosphatidylinositol 3-kinase mutations identified in human cancer are oncogenic. PNAS 102 802-807.

Karakas B, Bachman KE \& Park BH 2006 Mutation of the PIK3CA oncogene in human cancers. British Journal of Cancer 94 455-459.

Kasai T, Shimajiri S \& Hashimoto H 2000 Detection of SYTSSX fusion transcripts in both epithelial and spindle cell areas of biphasic synovial sarcoma using laser capture microdissection. Molecular Pathology 53 107-110.

Kato S, Iida S, Higuchi T, Ishikawa T, Takagi Y, Yasuno M, Enomoto M, Uetake H \& Sugihara K 2007 PIK3CA mutation is predictive of poor survival in patients with colorectal cancer. International Journal of Cancer 121 1771-1778.

Kontogeorgos G 2005 Classification and pathology of pituitary tumors. Endocrine 28 27-35.

Kontogeorgos G 2006 Predictive markers of pituitary adenoma behavior. Neuroendocrinology 83 179-188.

Kozaki K, Imoto I, Pimkhaokham A, Hasegawa S, Tsuda H, Omura K \& Inazawa J 2006 PIK3CA mutation is an oncogenic aberration at advanced stages of oral squamous cell carcinoma. Cancer Science 97 1351-1358.

Lai YL, Mau BL, Cheng WH, Chen HM, Chiu HH \& Tzen CY 2008 PIK3CA exon 20 mutation is independently associated with a poor prognosis in breast cancer patients. Annals of Surgical Oncology 15 1064-1069.

Ma YY, Wei SJ, Lin YC, Lung JC, Chang TC, Whang-Peng J, Liu JM, Yang DM, Yang WK \& Shen CY 2000 PIK3CA as an oncogene in cervical cancer. Oncogene 19 2739-2744.

Mambo E, Gao X, Cohen Y, Guo Z, Talalay P \& Sidransky D 2003 Electrophile and oxidant damage of mitochondrial DNA leading to rapid evolution of homoplasmic mutations. PNAS 100 1838-1843.

Massion PP, Kuo WL, Stokoe D, Olshen AB, Treseler PA, Chin K, Chen C, Polikoff D, Jain AN, Pinkel D et al. 2002 Genomic copy number analysis of non-small cell lung cancer using array comparative genomic hybridization: implications of the phosphatidylinositol 3-kinase pathway. Cancer Research 62 3636-3640.

Miller CT, Moy JR, Lin L, Schipper M, Normolle D, Brenner DE, Iannettoni MD, Orringer MB \& Beer DG 2003 Gene amplification in esophageal adenocarcinomas and Barrett's with high-grade dysplasia. Clinical Cancer Research 9 4819-4825.

Miyaki M, Iijima T, Yamaguchi T, Takahashi K, Matsumoto H, Yasutome M, Funata N \& Mori T 2007 Mutations of the PIK3CA gene in hereditary colorectal cancers. International Journal of Cancer 121 1627-1630.

Murugan AK, Hong NT, Fukui Y, Munirajan AK \& Tsuchida N 2008 Oncogenic mutations of the PIK3CA gene in head and neck squamous cell carcinomas. International Journal of Oncology 32 101-111.
Musat M, Korbonits M, Kola B, Borboli N, Hanson MR, Nanzer AM, Grigson J, Jordan S, Morris DG, Gueorguiev M et al. 2005 Enhanced protein kinase B/Akt signalling in pituitary tumours. Endocrine-Related Cancer 12 423-433.

Patel H, Polanco-Echeverry G, Segditsas S, Volikos E, McCart A, Lai C, Guenther T, Zaitoun A, Sieber O, Ilyas M et al. 2007 Activation of AKT and nuclear accumulation of wild type TP53 and MDM2 in anal squamous cell carcinoma. International Journal of Cancer 121 2668-2673.

Pei L, Melmed S, Scheithauer B, Kovacs K \& Prager D 1994 $\mathrm{H}$-ras mutations in human pituitary carcinoma metastases. Journal of Clinical Endocrinology and Metabolism 78 842-846.

Phillips WA, Russell SE, Ciavarella ML, Choong DY, Montgomery KG, Smith K, Pearson RB, Thomas RJ \& Campbell IG 2006 Mutation analysis of PIK3CA and PIK3CB in esophageal cancer and Barrett's esophagus. International Journal of Cancer 118 2644-2646.

Qiu W, Schönleben F, Li X, Ho DJ, Close LG, Manolidis S, Bennett BP \& Su GH 2006 PIK3CA mutations in head and neck squamous cell carcinoma. Clinical Cancer Research 12 1441-1446.

Qiu W, Tong GX, Manolidis S, Close LG, Assaad AM \& Su GH 2008 Novel mutant-enriched sequencing identified high frequency PIK3CA mutations in pharyngeal cancer. International Journal of Cancer 122 1189-1194.

Rooney PH, Murray GI, Stevenson DA, Haites NE, Cassidy J \& McLeod HL 1999 Comparative genomic hybridization and chromosomal instability in solid tumours. British Journal of Cancer 80 862-873.

Samuels Y \& Ericson K 2006 Oncogenic PI3K and its role in cancer. Current Opinion in Oncology 18 77-82.

Samuels Y, Wang Z, Bardelli A, Silliman N, Ptak J, Szabo S, Yan H, Gazdar A, Powell SM, Riggins GJ et al. 2004 High frequency of mutations of the PIK3CA gene in human cancers. Science 304554.

Samuels Y, Diaz LAJ, Schmidt-Kittler O, Cummins JM, Delong L, Cheong I, Rago C, Huso DL, Lengauer C, Kinzler KW et al. 2005 Mutant PIK3CA promotes cell growth and invasion of human cancer cells. Cancer Cell 7 561-573.

Santarpia L, El-Naggar AK, Cote GJ, Myers JN \& Sherman SI 2008 Phosphatidylinositol 3-kinase/AKT and ras/raf-mitogen-activated protein kinase pathway mutations in anaplastic thyroid cancer. Journal of Clinical Endocrinology and Metabolism 93 278-284.

Schönleben F, Qiu W, Ciau NT, Ho DJ, Li X, Allendorf JD, Remotti HE \& Su GH 2006 PIK3CA mutations in intraductal papillary mucinous neoplasm/carcinoma of the pancreas. Clinical Cancer Research 12 3851-3855.

Shayesteh L, Lu Y, Kuo WL, Baldocchi R, Godfrey T, Collins C, Pinkel D, Powell B, Mills GB \& Gray JW 1999 PIK3CA is implicated as an oncogene in ovarian cancer. Nature Genetics 21 99-102.

Suhardja A, Kovacs K \& Rutka J 2001 Genetic basis of pituitary adenoma invasiveness: a review. Journal of Neuro-Oncology 52 195-204. 
Tamura M, Gu J, Takino T \& Yamada KM 1999 Tumor suppressor PTEN inhibition of cell invasion, migration, and growth: differential involvement of focal adhesion kinase and p130Cas. Cancer Research 59 442-449.

Tena-Suck ML, Ortiz-Plata A \& de la Vega HA 2008 Phosphatase and tensin homologue and pituitary tumortransforming gene in pituitary adenomas. Clinicalpathologic and immunohistochemical analysis. Annals of Diagnostic Pathology 12 275-282.

Vasko V, Saji M, Hardy E, Kruhlak M, Larin A, Savchenko V, Miyakawa M, Isozaki O, Murakami $\mathrm{H}$, Tsushima $\mathrm{T}$ et al. 2004 AKT activation and localisation correlate with tumour invasion and oncogene expression in thyroid cancer. Journal of Medical Genetics 41 161-170.

Velho S, Oliveira C, Ferreira A, Ferreira AC, Suriano G, Schwartz S Jr, Duval A, Carneiro F, Machado JC, Hamelin R et al. 2005 The prevalence of PIK3CA mutations in gastric and colon cancer. European Journal of Cancer 41 1649-1654.

Wilson CB 1984 A decade of pituitary microsurgery: the Herbert Olivercrona lecture. Journal of Neurosurgery 61 814-833.

Woenckhaus J, Steger K, Werner E, Fenic I, Gamerdinger U, Dreyer T \& Stahl U 2002 Genomic gain of PIK3CA and increased expression of p110alpha are associated with progression of dysplasia into invasive squamous cell carcinoma. Journal of Pathology 198 335-342.

Wu G, Mambo E, Guo Z, Hu S, Huang X, Gollin SM, Trink B, Ladenson PW, Sidransky D \& Xing M 2005 Uncommon mutation but common amplifications of the PIK3CA gene in thyroid tumors. Journal of Clinical Endocrinology and Metabolism 90 4688-4693. 